\title{
TRANSLATION TOOL TECHNOLOGY TREND: WHAT ARE THE IMPACTS FOR THE STUDENTS?
}

\author{
Eka Uliyanti Putri Br Bangun 1*, Siti Maisaroh Mustafa ${ }^{2}$ \\ 'LP3i Tangerang, Tangerang, Indonesia \\ 2STMIK Bina Sarana Global, Tangerang, Indonesia \\ *ekauliyanti@gmail.com
}

\begin{tabular}{|c|c|}
\hline Article Info & ABSTRACT \\
\hline $\begin{array}{l}\text { Article history } \\
\text { Received: December 3, } 2020 \\
\text { Revised: December 22, } 2020 \\
\text { Accepted: December 28, } 2020\end{array}$ & $\begin{array}{l}\text { The popularization of the computer and its technology have } \\
\text { brought about some significant changes. Technology itself } \\
\text { has impacted almost every aspect of life today, } \\
\text { and education is no exception. Technology provides not only }\end{array}$ \\
\hline $\begin{array}{l}\text { Keywords: } \\
\text { Impacts; } \\
\text { Translation Tools; } \\
\text { Translation; } \\
\text { Writing Skill. }\end{array}$ & $\begin{array}{l}\text { learning resources. Regarding English learning, translation is a } \\
\text { part of learning activities in which students sometimes assigned } \\
\text { for translation work. Hence, a specific translation tool, namely } \\
\text { Google translate, is preferred and utilized. This research aims } \\
\text { to examine the impacts of using the translation tool for students } \\
\text { and how frequently they use it in their learning activities. It is } \\
\text { quantitative research and the methods of the data collections } \\
\text { comprised tests, additional interviews and questionnaires. The } \\
\text { samples of this research were } 40 \text { students at LP3l. It was evident } \\
\text { that the translation tool had positive impacts on the students. } \\
\text { The data could derive from the results of Pre-test and Post-test } \\
\text { of the students. They got a higher score before and after using } \\
\text { the translation tool. Although translation tool had good } \\
\text { impacts for students, some problematic points were using the } \\
\text { translation tool. Students suggested to check and recheck the } \\
\text { result of their translation in the target language. The translation } \\
\text { tool also helped students do writing tasks, even though there } \\
\text { was some positive and negative impact on students' } \\
\text { translation tool utilization. }\end{array}$ \\
\hline
\end{tabular}

\section{INTRODUCTION}

In recent years, technology has played an enormous role in the business and the education sector. Technology helps people ease, more efficient, and practical work results, making it an inseparable part of day-to-day routines. Particularly in education, the term educational technology refers to the use of technology in the educational setting. With the use of technology in the classrooms, students will better engage in the subject taught, increase students' productivity by providing them with the learning tools they need and succeed in the learning process. In return, technology also helps reduce wasted time, energy, and money while encouraging and rewarding hard work. Additionally, technology is said to infuse classrooms with digital learning tools, such as computers, handheld devices, and it also expands course offerings, experiences, and learning materials.

The parts of technological features that become beneficial in education is the availability of several translation tools such as Microsoft Language Portal, SmartCAT, 
Memsource, The Free Dictionary, Fluency Now and the most frequently utilized: Google Translate. Technology has led very quickly to its use for the translation field. Hatim and Munday (2004) stated that the increasing globalization and the impact of the internet had popularized fast translations of promotional literature, technical manuals, webpage and other all ranges of communication into other languages. Research in translation technology, especially in machine translation, is often carried out by several research types investigating the frequency and the effectiveness of the translating machines. As one of translating machines mentioned formerly, CAT tools have an essential role in the translation field. Le Blanc (2013) stated that CAT tools could influence the translation process and the ways translations produced nowadays.

The translation that is a part of particularly language learning has been a subject taught in higher education in which students sometimes need a helpful tool in their work. House (2015) explained that translation is a linguistic act and an act of communication in cultures. She further revealed that translation is a cognitive procedure which occurs in human beings. Chellappan (1991) stated that translation creates learners' awareness of the similarities and differences between them. It is facilitative for learners to discover how to use grammatical structure correctly and vocabulary items appropriately. He added that translation helps learners through contrastive analysis and systematic comparison between two languages in terms of their morphology, syntax, and semantics. In response to the research conducted regarding the use of translation technology, the designed research explores how translation tool technology affects students' writing and how they respond to the translation tool.

\subsection{Theoretical Background}

They were writing a fundamental skill that must be a mastery of EFL learners besides listening, speaking and reading. Among the four skills learned, writing is still a challenge students have to face. EFL learners' weakness appears when they transfer their ideas from Bahasa to English naturally because the context or the word choices are sometimes not appropriate. Lack of vocabulary the majority of students encounter is also one of the underlying reasons. This case is crucial as English, quite frequently, is only used in the learning process during the classroom instructions, whereas there is little intention of using English outside the class so that the habit is hardly formed (Chen et al., 2005). Insufficient exposures to writing outside the classroom contribute to the ability of students producing written work.

As for the translation activity, which is also part of the writing tasks, Baker (1992) stated that an adequate translation is a translation that fulfils specific parameters. He further explained the parameters: Equivalence at Word Level Word, Equivalence at phrases level, and Textual Equivalence that comprises Cohesion and Pragmatic Equivalence. One of the researches conducted in his purpose research was exploring students' attitudes towards translation in the context of language learning (Josefsson, 2011). A myriad of theories can help

IJEMI Vol.2, No.1, January 2021, pp. 77 87 
a translation work conducted effectively, and some suggested using translation tools under certain circumstances.

Husain (1995) revealed that particular English as a foreign language (EFL) learners could quickly and efficiently analyze and comprehend the target language's complex structure. However, students should be well-executed with translation work strategies, resulting in good quality and correct translation. Adequate knowledge could be very beneficial, though, even when they later utilize a translating machine to assist them with translation endeavours. Liao (2006) and Chern (1993) once described a learning atmosphere in a Taiwanese EFL college. The students there frequently transferred certain English words and phrases into Chinese translation in their textbooks' margins to help them remember the meanings well. Students have employed various techniques regarding translation activities. However, the availability of particular translation tools plays significant roles in assisting students with translation work.

To respond to all of the statements from several types of research concerning translation and EFL learners' weakness in their writing skill, Translation tool application is one of communication technology machine that helps the readers understand foreign language text, as stated by Pym (2011). Mahardika (2017) put forward that translation is a software system in which it can predict the translation words from one language to another. In line with another research about EFL learners' perception regarding translation tool, Marito and Ashari (2017) found out in their research, that translation tool was handy and helpful, as it could consider the users to know the meaning of words, phrases and clauses. Additionally, the student used the translation tool to alternative medium in translating word, phrase and sentences. This tool for helping in transl language (source language) in another language (target language) serves as an assisting device that enables students to get more exposure to various lexicons and clauses. As an effective strategy, the translation should ideally lower or reduce foreign language learning anxiety. It is another point to consider since anxiety can prevent students from producing the expected outcome. Furthermore, the real usefulness of translation in English classes lies in exploiting it to compare grammar, vocabulary, word order and other language points in English and the student's mother tongue. Hence, the complexity in translation can reduce by providing helpful aids.

There are other abundant benefits of using technology in teaching as argued by Warschaver et al. (2000). The first is to help students to be active and creative, while at the same time building mastery in technology to receive vast information and knowledge. Second, technology develops autonomous learning strategies for students to be independent learners. Independence in learning can accommodate the presence of a helpful device. Third, students can learn communication and teamwork skills by using technology. Fourth, the importance of cross-cultural learning can help to communicate with people from different cultures, and it interprets information from diverse cultural contexts. The last is the importance 
of critical learning skills by considering how new information technologies help the social problem, political and economic contexts in a broader sense.

Concerning the utilization of technology, Vrasidas and Mclasaac (2001) explained that technology had influenced our life and environment, for instance, informing policy at the workplace, and curriculum design at schools. Undoubtedly, the existence of technology can support EFL learners to study. The English foreign language translation skill highly considered to achieve intercultural communication. The development of technology that became more irreplaceable nowadays will help create some tools to ease students' assignments. One of them is translation tool applications that students can access to accomplish, among others, the writing assignment. It indeed affects the education field's improvement, and progression as the presence of technology has now become such an inseparable part.

\section{METHOD}

\subsection{Participants}

The sample of the research comprised 40 students studying at Lp3i Tangerang. This research conducted in the second semester where diploma students had English as one of the core subjects. The research commenced in January and ended in April 2020. The participants divided into two groups: The experimental group and The control group. Each group had the same number of participants. The experimental group consisted of 20 students who were taught by the translation tool in their writing activities. The control group consisted of another 20 students who taught using a traditional teaching method. Besides, both groups followed guidance from the same teacher and received the same materials and assignments with precisely the same meeting hours.

\subsection{Instruments}

In this research, the researcher applied a quantitative approach. According to Frankle and Wallen (2006), quantitative research can categorize as either descriptive or experimental research. Descriptive research aims to become more familiar with phenomena, obtain perceptions, and formulate a more specific research problem or hypothesis. In contrast, experimental research is to test cause and effect relationships among variables. Quantitative research involves studies that use statistical analyses to obtain their findings, including formal, systematic measurement supported by statistics. Furthermore, Denzin and Lincoln (2005) reinforced that quantitative studies emphasize the measurement and analysis of causal relationships between variables, not processes. Unlike the qualitative approach, which emphasizes the qualities of entities, the process, and meanings, the quantitative approach focuses on the result, which can be generalized statistically.

In regards to this, the present research fully adapts the concept, focusing on using the translation tool and how they respond to the tool. The research focused on the research results 
regarding the efficacy of a translation tool indicated in the students' tests. This research design the effects of another variable. In this case, the experiment class chose randomly. The researcher investigated two classes: The experimental class and The control class. The experimental class was the class that gave treatment using the translation tool, while the control class was the class that taught using the typical teaching method.

There were two instruments in this research: tests and questionnaire. The first instrument was the test which used to assess students' abilities. The second instrument in this research was a questionnaire. The researcher used the Likert scale to find out the students' responses towards the translation tool. The designed questionnaire consisted of 20 items with five rating scale of replies (1=strongly disagree, $2=$ disagree, $3=$ neither agree nor disagree, $4=$ agree and $5=$ strongly agree). The Likert items used to measure respondents' responses to particular questions and statements.

\subsection{Procedures}

In the experimental group, students taught by using the translation tool. The procedures were as seen in Table 1.

Table 1. Procedures In Conducting The Research

\begin{tabular}{|c|c|}
\hline \multirow{2}{*}{\multicolumn{2}{|c|}{91}} \\
\hline & \\
\hline & $\begin{array}{ll}\text { a. } & T \\
\text { b. }\end{array}$ \\
\hline Me & 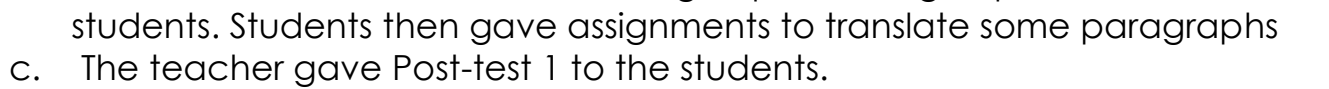 \\
\hline & to the students. \\
\hline Meeti & teacher gave Post-test 2 to the students. \\
\hline
\end{tabular}

By quantitative descriptive research and the type of data source of this research, the data collection techniques used included: Tests, questionnaire and additional interview.

The data collection, two instruments were used in this research. They were writing test and questionnaire. Writing test was projected to elicit and collect information on students' writing skills before and after treatment. Meanwhile, the questionnaire used to find out students' responses. The test, there were two tests designed in this research, namely Pre-test and Post-test. The researcher ascertained that the pre-test provided instructions that differed in forms or wordings from the Post-test, though the two tests must examine the same contents, e.g., alternative forms of a test for the same groups.

The investigation of the translation tool's impact in this research analyzed the data from students' Pre-test, and Post-test scores, the data obtained from both occasions analyzed using Paired Samples T-Test in IBM SPSS. The second instrument was a questionnaire, and these instruments were analyzed by using Likert Scale. 


\subsection{Data Analysis}

Researches used professional translation assessment to grade the student translations based on research conducted by Lai in 2008. After reading the text, students asked to translate two paragraphs of the original text into English. Their translation was scored based on the principles of a 6/4 scale (6 grades for "accuracy" and four grades for "expression") Lai (2008) had developed. Tables 2 and 3 provided the criteria used to assess the translation quality for accuracy and expression. Translation of expression, the translated sentences must be "readable" and "understandable." Points awarded on a sentence-by-sentence basis. The two paragraphs translated in this experiment consisted of 10 sentences for a total score of 100 .

Table 2. Translation Accuracy

\begin{tabular}{cl}
\hline Score & \multicolumn{1}{c}{ Criteria } \\
\hline 6 & Messages in translation almost match the original with no errors \\
5 & Messages in translation almost match the original, but with one minor error \\
4 & $\begin{array}{l}\text { Messages in the translation are different from the original, with two (or above) minor } \\
\text { errors }\end{array}$ \\
3 & $\begin{array}{l}\text { Messages in the translation are different from the original, with one significant error } \\
\text { and three (or above) minor errors }\end{array}$ \\
2 & $\begin{array}{l}\text { Messages in translation vary significantly from the original, with two significant errors } \\
\text { or only pile-up descriptions } \\
\text { Messages in the translation are different from the original or with much missing in } \\
\text { translation }\end{array}$ \\
\hline
\end{tabular}

Table 3. Translation Expression

\begin{tabular}{cl}
\hline Score & \multicolumn{1}{c}{ Criteria } \\
\hline 4 & The translation is clear and understandable with appropriate usage, register, \\
collation, and punctuation & $\begin{array}{l}\text { The translation is generally clear and understandable, but with one or two errors in } \\
\text { usage and expression, typos, or redundant word }\end{array}$ \\
2 & $\begin{array}{l}\text { The translation is barely understandable, but with syntactical errors and } \\
\text { inappropriate usage and expression }\end{array}$ \\
1 & The translation is ungrammatical and difficult to understand, with many omissions \\
\hline
\end{tabular}

\section{RESULTS}

\subsection{Findings and Discussions.}

This section presents findings and discussion of the research regarding students' impact and responses using the translation tool.

Research Question 1: to what extent does translation tool technology affect students' writing?

Table 4. Mean Scores of Pre And Post-Test

\begin{tabular}{llllc}
\hline Group & N & Pre Test & Posttest 1 & Posttest 2 \\
\hline Control & 20 & 74 & 73.85 & 74.2 \\
Experiment & 20 & 75 & 84 & 87 \\
\hline
\end{tabular}


Based on table 4, column 1 showed the results of Pre-test and Post-test for both groups. Pre-test mean scores of students in the control group and experimental group were 74 and 75 . Post-test mean scores of students in the control group and experimental group were 78.45 and 84. The Post-test 2 showed scores of students in control, and experimental groups were around 74.2 and 87. Therefore, it could conclude that there were different scores between Pre-test and Post-test.

Table 5. Independent T-Test

\begin{tabular}{lllll}
\hline & $N$ & $T$ & Sig. (2-tailed) & Sig \\
\hline Levene's test for equality of variances & 20 & 7.641 & 0.000 & 0.849 \\
\hline
\end{tabular}

Based on table 5, the independents' samples test above showed that the probability (Sig. (2-tailed)) was less than level significance. Thus, it could conclude that the null hypothesis of no improvement rejected, the alternative hypothesis was accepted, or in other words, both control and experimental groups significantly improved. The result of t-test was 7.641. The ttable was 1.734 (sum N-2 = 18), analyzed of the t-test Post-test were 7,641>1,734 the value of t-test was more than t-table t-test, it meant that the value of t-test was significant. The alternative hypothesis was accepted. There was no significant post-test score between control and experimental class, which meant that Ha was the translation tool to impact the students' writing.

From the above elaboration, it could conclude that there was a difference in the average number of scores before and after using the translation tool. The students translated text with translation tool had different scores with the other students who did not use the translation tool.

Research Question 2: How do students respond to the use of the translation tool?

Table 6. Mean Scores of Motivation

\begin{tabular}{llll}
\hline No & Statement & $\mathrm{x}$ & $\mathrm{sd}$ \\
\hline 1 & Translation to; the help on the translation task & 4.85 & 0.366 \\
2 & I can translate word to word & 4.85 & 0.366 \\
3 & Translation tools are effortless to use & 4.50 & 0.513 \\
4 & It helps to find the new words & 4.30 & 0.657 \\
5 & It is easy and straightforward to use & 4.75 & 0.444 \\
6 & I can translate well & 4.50 & 0.513 \\
7 & It helps to shorten the time when translating a long text & 4.60 & 0.598 \\
& & & \\
\hline 8 & It helps in the work and study of the language & 4.75 & 0.444 \\
9 & It can assist in doing assignment quickly & 4.40 & 0.821 \\
10 & It can use in urgent conditions & 4.85 & 0.366 \\
11 & It can search for new words easily and quickly & 4.50 & 0.513 \\
12 & It can translate words or sentences quickly & 3.85 & 0.366 \\
13 & It helps to understand the grammar & 4.00 & 1.076 \\
14 & It makes me feel lazy to use a dictionary & 3.90 & 1.071 \\
15 & It can increase interest to study English & 4.25 & 0.851 \\
16 & I can check grammar with the translation tool & 3.30 & 0.865
\end{tabular}




\begin{tabular}{llll}
\hline No & Statement & $x$ & sd \\
\hline 17 & It always translates sentences with correct grammar & 2.85 & 0.933 \\
18 & I sometimes find misunderstanding in the meaning & 4.00 & 0.795 \\
19 & I sometimes could not find the meaning & 4.25 & 0.444 \\
20 & I will always use the translation tool in the next assignment & 4.25 & 0.444 \\
\hline
\end{tabular}

According to Table 6, the overall mean score indicated that students had positive responses to the translation tool. There were several students answered strongly agree and agree in their opinion to the learning process. The highest score for the items number 1, 2 and 10, meaning that almost all students thought translation tool was useful for them. They got enjoyment in studying English and translating texts with the utilization of the translation tool. Translation tool could help students when they were doing the translation task. Moreover, students could translate word to word and that the tool could use in urgent condition. The translation tool helped their work and study of language because it was practically easy and straightforward.

\section{DISCUSSIONS}

The researchers conducted some additional interviews with some students, and the interview consisted of three questions to be answered. The first question was, What translation tool usually use most? the second one was why do you use that translation tool for doing the task? The last one: What is the strength of the translation tool in learning English?

Based on the data, most students frequently used certain kinds of translation tools. The most preferred translation tool used is a translating machine called Google translate, an online translation tool. Preferred by the students, Google Translate uses a statistical translation model, like many other successful OT applications, which takes the word or words to translate and searches a bilingual text corpus for that word or words. It returns the most likely match as a result, with information such as what part of speech the word or words is, the definition, suggestions for other phrases, and other possible translations of the word-using-using online translation to support for language learning and to reduce the amount of time required to discover new vocabulary, which can result in an increased comprehension of a text. In conclusion, the students had more time to pay attention to the whole passage or text that they wanted to read, instead of focusing on the word to the word simultaneously.

For the second question, the reason for the use of translation tool application by the EFL learners who translated from Bahasa to English text, or from an English text to Bahasa, for instance, was because they lack English vocabulary and that the tool could assist them in searching for new words not only more easily and quickly, but also in a more practical way. The participants also described that they felt at ease through translation tool application, and the provided answers were reliable and considerable. Some of the students stated that the word choices were appropriate with the context. Google Translate allowed students to speedy

IJEMI Vol.2, No.1, January 2021, pp. 77 87 
access to a dictionary, and it helped produce faster results. Moreover, Google translates facilitated access to more different vocabulary and phrases. Using Google Translate as a trend tool to discover new vocabulary allowed students to build their knowledge, as they could search for words that they wanted to learn, in addition to words the teacher required them to learn (Peters et al., 2011).

To answer the first research question, the researcher conducted the test (Pre-test and Post-test). Based on the pre-test data, almost all students translated the text with different results of the target language. Messages in translation varied significantly from the original, with two significant errors or only pile-up descriptions and different from the original or with much missing in translation. Their translation was then barely understandable, but with syntactical errors and inappropriate usage and expressions. After they used the translation tool, their translation work was getting better. Their translation was generally clear and understandable, but with one or two errors in usage and expression, typos, or redundant words and understandable with appropriate usage, register, collocation, and punctuations.

This translation tool's strength was an easy and fast tool to find out the meaning of the words. It also helped the students to know how to pronounce the words. Google translate could also be used through smartphone or laptop anywhere, such as in their classroom, canteen, home and other possible places. It was effortless to help them to understand the unfamiliar words by themselves. With this tool, students used the translation tool to complete their English exercises and assignments while also reducing the tension and anxiety in learning.

These findings were in line with Josefsson (2011), who stated that students mostly used Google translate for text translation because it was proven to be quick. Some of them used the translation tool to get a better understanding of the language of the text. In the translation work, students frequently used Google translate or translation tool to quickly get into the target language without looking up the physical dictionaries.

Moreover, some students revealed that they liked to study English with the translation tool. This statement correlated with one of the questionnaire statements that they enjoyed studying English and translated texts with a translation tool. It could help students when they were doing the translation task. Additionally, students were able to use it in an emergency. Marito and Ashari (2017), who also conducted this kind of research, found that learners' perception of translation tool was useful in urgent condition. Besides, the translation tool helped their work and study of language because it was easy and straightforward to use.

Some drawbacks were also reported based on the questionnaires. Students highlighted that translation tool could not translate all words correctly, and it sometimes gave inappropriate or misunderstanding word meanings, so students needed to recheck the meanings. Most of the students answered disagree because the translation tool did not always translate sentences with correct grammar on the questionnaire's statement. Students sometimes could not find the meaning when they looked up words in the target language. 
Furthermore, there was a negative impact on the students in using the translation tool. Several students responded they agree that translation tool made them lazy to use the physical dictionary. However, some other students strongly agreed that translation tool could increase their interest to study English.

\section{CONCLUSIONS}

In conclusions, from the research conducted and the whole data analyzed, it could state that students realized translation tool could help in their English learning and in completing the given tasks. It was evident that the translation tool had positive impacts on the students. The data could derive from the results of Pre-test and Post-test of the students. They got a higher score before and after using the translation tool. Students in the control group got a lower score than students in the experiment group because they did not use the translation tool. Instead, they used physical dictionaries to help them in translating the texts.

On the other hand, the students in the experimental group used translation tool, and the results could see in the scores they got after they did the Post-test 1 and Post-test 2. Although translation tool had good impacts for students, some problematic points were using the translation tool. Students were reluctant to look up words meaning using the physical dictionary. Furthermore, the translation tool sometimes translated certain words, phrases or clauses inaccurately and inappropriately. Students suggested to check and recheck the result of their translation in the target language. Students should be wiser and be more careful in using the translation tool for their writing tasks.

\section{REFERENCES}

Cahyaningrum, I. O., \& Widiyantari, Y. (2018). Comparison of Translation Quality between Google Translate, SDL Free Translation and Tradukka in the Health Article EntitledVaginal Birth After Caesarean. In English Language and Literature International Conference (ELLiC) Proceedings (Vol. 2, pp. 521-525).

Chandra, S. O., \& Yuyun, I. (2018). The use of google translates in EFL essay writing. LLT Journal: A Journal on Language and Language Teaching, 21 (2), 228-238.

Chellappan, K. (1991). The role of translation in learning English as a second language. International Journal of Translation, 3, 61-72.

Chern, C. L. (1993). Chinese students" word-solving strategies in reading in English. In T. Huckin $\& M$.

Chen, J. F., Warden, C. A., \& Chang, H. T. (2005). Motivators that do not motivate: The case of Chinese EFL learners and the influence of culture on motivation. TESOL Quarterly, 39(4), 609-633. 
Dehbashi Sharif, F., \& Salehi, F. (2015). The Effect of the Translation Technologies on the Critical Thinking of the Students of the Translation Studies. Journal of Language and Translation, 5(1), 95-109.

Denzin, N. K., \& Lincoln, Y. S. (2005). The Sage handbook of qualitative research (3rd ed.). Sage Publications Ltd.

Frankel, J. R., \& Wallen, N. E. (2006). How to Design and Evaluate Research in Education. McGraw Hill.

Hatim, B., \& Munday, J. (2004). Translation: An advanced resource book. Psychology Press.

Haynes \& J. Coady (Eds.), Second language vocabulary learning (pp. 67-81). Norwood, NJ: Ablex.

House, J. (2015). Translation as communication across languages and cultures. Routledge.

Husain, K. (1994). Assessing the role of translation as a learning strategy in ESL. International Journal of Translation, 1 (2): 59-84.

Lai, T. Y. (2008). Comparisons of four translation assessment scales. Compilation and Translation Review, 1 (1), 71-92.

Liao, P. (2006). EFL learners" beliefs about and strategy use of translation in English learning. RELC, 37(2), 191-215.

Josefsson, E. (2011). Contemporary Approaches to Translation in the Classroom: A Study of Students' Attitudes and Strategies 1-32. Retrieved on November 4, 2017, from http://www.diva-portal.org/smash/get/diva2:519125/FULLTEXTO1.pdf.

Mahardika, R. (2017). The Use of Translation Tool in Efl Learning: Do Machine Translation Give Positive Impact in Language Learning?. Pedagogy: Journal of English Language Teaching, 5(1), 49-56.

Marito, S., \& Ashari, E. (2017). Efl students perception about machine translation. Jurnal Dimensi, 6(2)

Pan, Y. C., \& Pan, Y. C. (2012). The use of translation in the EFL classroom. The Philippine ESL Journal, 9, 4-23.

Peters, M., Weinberg, A., Sarma, N., \& Frankoff, M. (2011). From the Mouths of Canadian

University Students: Web-based Information-seeking Activities for Language Learning.

CALICO Journal, 28(3), 621-638. Retrieved from

https://journals.equinoxpub.com/index.php/CALICO

Pym, A. (2011). What Technology Does to Translating. The International Journal for Translation \& Interpreting Research. Vol 3 No 1, 1-9

Vrasidas, C., Mclsaac, M. S. (2011). Integrating Technology in Teaching and Teacher Education: Implications for Policy and Curriculum Reform. Education Media International ISSN 0952-3987 print/ISSN 1469-5790

Warschaver, M., Shetzer, H., and Meloni, C. (2000). Internet for English Teaching. Virginia: Teachers of English to Speakers of Other Languages, Inc. 